\title{
Complete genome sequence and comparative analysis of Acetobacter pasteurianus 386B, a strain well-adapted to the cocoa bean fermentation ecosystem
}

\author{
Koen Illeghems, Luc De Vuyst and Stefan Weckx
}

\begin{abstract}
Background: Acetobacter pasteurianus 386B, an acetic acid bacterium originating from a spontaneous cocoa bean heap fermentation, proved to be an ideal functional starter culture for coca bean fermentations. It is able to dominate the fermentation process, thereby resisting high acetic acid concentrations and temperatures. However, the molecular mechanisms underlying its metabolic capabilities and niche adaptations are unknown. In this study, whole-genome sequencing and comparative genome analysis was used to investigate this strain's mechanisms to dominate the cocoa bean fermentation process.
\end{abstract}

Results: The genome sequence of $\mathrm{A}$. pasteurianus 386B is composed of a 2.8-Mb chromosome and seven plasmids. The annotation of 2875 protein-coding sequences revealed important characteristics, including several metabolic pathways, the occurrence of strain-specific genes such as an endopolygalacturonase, and the presence of mechanisms involved in tolerance towards various stress conditions. Furthermore, the low number of transposases in the genome and the absence of complete phage genomes indicate that this strain might be more genetically stable compared with other A. pasteurianus strains, which is an important advantage for the use of this strain as a functional starter culture. Comparative genome analysis with other members of the Acetobacteraceae confirmed the functional properties of $A$. pasteurianus 386B, such as its thermotolerant nature and unique genetic composition.

Conclusions: Genome analysis of A. pasteurianus 386B provided detailed insights into the underlying mechanisms of its metabolic features, niche adaptations, and tolerance towards stress conditions. Combination of these data with previous experimental knowledge enabled an integrated, global overview of the functional characteristics of this strain. This knowledge will enable improved fermentation strategies and selection of appropriate acetic acid bacteria strains as functional starter culture for cocoa bean fermentation processes.

Keywords: Acetobacter pasteurianus, Cocoa bean fermentation, 454 pyrosequencing

\section{Background}

Acetic acid bacteria (AAB) are a group of microorganisms that belong to the family of the Acetobacteraceae of the Alpha-proteobacteria [1]. AAB can be found on (tropical) fruits and flowers [2-4], in fermented foods [1,3], and as members of the Drosophila gut [5]. Overall, AAB are of industrial interest because of their physiology, which is the

\footnotetext{
* Correspondence: Stefan.Weckx@vub.ac.be

Research Group of Industrial Microbiology and Food Biotechnology (IMDO), Faculty of Sciences and Bio-engineering Sciences, Vrije Universiteit Brussel, Pleinlaan 2, Brussels B-1050, Belgium
}

\section{Biomed Central}

(C) 2013 Illeghems et al.; licensee BioMed Central Ltd. This is an Open Access article distributed under the terms of the Creative Commons Attribution License (http://creativecommons.org/licenses/by/2.0), which permits unrestricted use, distribution, and reproduction in any medium, provided the original work is properly cited. case for acetic acid production out of ethanol during vinegar, kombucha, or cocoa bean fermentation [6-8] as well as for fine chemical productions such as those of ascorbic acid and cellulose $[9,10]$. Furthermore, AAB can occur as spoilage bacteria, as can be the case in beer, wine, and cider fermentations [1,3]. One of the key metabolic features of $\mathrm{AAB}$ is the conversion of ethanol into acetic acid by two sequential reactions catalyzed by membranebound alcohol dehydrogenase (ADH) and aldehyde dehydrogenase (ALDH) enzymes [11]. 
Currently, AAB include twelve genera, among which Acetobacter, Gluconobacter, and Gluconacetobacter are the most studied ones $[3,8,12]$. The genus Acetobacter is one of the most interesting from a biotechnological point of view $[1,3]$, because of its ability to oxidize ethanol into acetate while tolerating high acetic acid concentrations in the environment [13]. Different species within the Acetobacter genus are distinguished, among which Acetobacter pasteurianus, Acetobacter aceti and Acetobacter pomorum are important in industrial vinegar production $[3,14,15]$, Acetobacter cerevisiae is present in beer and on grapes [16,17], and Acetobacter tropicalis and Acetobacter senegalensis are involved in the cocoa bean fermentation process [18]. Acetobacter species are able to oxidize acetate completely (so-called overoxidation) and use ubiquinones of the Q-9 type, the latter being in contrast with species of the AAB genera Gluconacetobacter and Gluconobacter that contain mainly ubiquinones of the Q-10 type [19]. At present, A. pasteurianus IFO 3283 (originating from a fermentation) is the only member of the genus Acetobacter of which the genome has been sequenced completely, including six plasmids [20]. However, draft genomes are available for $A$. pasteurianus 3P3 (originating from submerged wine vinegar) [21], A. pasteurianus NBRC 101655 (Thai pineapple) [22], A. pasteurianus subsp. pasteurianus LMG $1262^{\mathrm{T}}$ (Dutch beer, type strain) [21], A. aceti NBRC 14818 (ethanol-based vinegar) [23], A. pomorum DM001 (Drosophila gut) [5], and A. tropicalis NBRC 101654 (Thai fruit) [2,24]. In general, Acetobacter species possess relatively small genomes (approximately $3 \mathrm{Mb}$ ), including plasmids in particular cases [20,25-27].

Acetobacter pasteurianus strains are used for vinegar fermentations worldwide [28-30] and also occur in beer as spoilers [3]. Further, it has been shown that this species plays an essential role in the fermentation of cocoa pulpbean mass, the first step in chocolate production [31-33]. Spontaneous cocoa bean fermentation is characterized by a succession of microbial activities carried out by yeasts (in particular Hanseniaspora opuntiae/uvarum and Saccharomyces cerevisiae), involved in depectinization and ethanol formation; lactic acid bacteria (LAB, in particular Lactobacillus fermentum), involved in citric acid and fructose conversion and lactic acid production; and $\mathrm{AAB}$ (in particular $A$. pasteurianus), involved in the oxidation of ethanol produced by the yeasts into acetic acid and further overoxidation of acetic acid and lactic acid produced by LAB into carbon dioxide and water [6,34].

Acetobacter pasteurianus 386B originates from a spontaneous cocoa bean heap fermentation carried out in Ghana and has been characterized as an ethanol-oxidizing, lactic acid-oxidizing, and acetic acid-producing strain [18,35]. Furthermore, A. pasteurianus 386B is a thermotolerant strain with high resistance to ethanol and acetic acid [36,37]. These functional properties make it an ideal starter culture strain for cocoa bean fermentations [38]. In this study, we present the complete genome sequence and analysis of A. pasteurianus $386 \mathrm{~B}$ to obtain insights into the genomic features of this interesting starter culture strain $[37,38]$. A better understanding of the molecular mechanisms underlying its metabolic capabilities will lead to detailed insights into the mechanisms of niche adaptation of this strain. Furthermore, comparison of A. pasteurianus $386 \mathrm{~B}$ with other sequenced members of the Acetobacteraceae will address the unique functional properties of this strain as well as the common characteristics of the Acetobacteraceae.

\section{Results and discussion}

\section{Pyrosequencing and sequence annotation}

The 454-pyrosequencing run of the A. pasteurianus 386B genomic DNA yielded 217,169 reads with a total number of $72,387,894$ bp that were assembled into 10 scaffolds, consisting of 118 large (> 500 nucleotides) contigs and 25 small (100-500 nucleotides) contigs. Computational analysis of the sequence assembly indicated the presence of seven plasmids. The gaps in the chromosome and plasmids were closed by PCR assays followed by sequencing of the corresponding amplicons, resulting in a final assembly of the circular chromosome with a size of 2,818,679 bp and the seven plasmids ranging in size from $3,851 \mathrm{bp}$ to 194,780 bp (Table 1; Figure 1A). Gene finding and annotation of the A. pasteurianus 386B genome with the GenDB software resulted in 2,595 and 280 protein-coding sequences (CDS) for the chromosome and plasmids, respectively. Furthermore, five ribosomal RNA ( $r r n)$ operons were detected and 57 tRNA genes were predicted. Clustered regularly interspaced short palindromic repeats (CRISPRs) were not found. Relevant features deduced from the genome sequence of $A$. pasteurianus $386 \mathrm{~B}$ are summarized in Table 2.

\section{General architecture of the $A$. pasteurianus 386B genome} A plot of the calculated $\mathrm{G} / \mathrm{C}$ skew $[(\mathrm{G}-\mathrm{C}) /(\mathrm{G}+\mathrm{C})]$ indicated a bidirectional replication mechanism of the chromosome (Figure 1A), which was confirmed by the biased distribution of architecture imparting sequences (AIMS) on the leading and lagging strands [39], dividing the chromosome of $A$. pasteurianus 386B into two replichores of similar sizes (Figure 1B). This enabled the prediction of the origin of chromosomal replication (oriC), located near the dnaA-coding region (APA386B_66), as well as a replication termination (dif) region at position $1,590,515$ on the chromosomal map [40]. The sequence of the 32-bp dif region was aligned with the consensus sequence of Gamma-proteobacterial dif sites [41]. The dif region, positioned opposite of the oriC, is involved in replication termination and defines the leading and 
Table 1 General features of the Acetobacter pasteurianus 386B chromosome and plasmids

\begin{tabular}{lllll}
\hline Name abbreviation & $\begin{array}{l}\text { EMBL } \\
\text { accession no. }\end{array}$ & Contigs & Size (bp) & GC (\%) \\
\hline APA386B (chromosome) & HF6775770 & 78 & 2818679 & 52.91 \\
APA386B_1P (plasmid) & HF677571 & 45 & 194780 & 52.01 \\
APA386B_2P (plasmid) & HF677572 & 6 & 18169 & 55.57 \\
APA386B_3P (plasmid) & HF677573 & 15 & 15601 & 55.47 \\
APA386B_4P (plasmid) & HF677574 & 5 & 11105 & 52.28 \\
APA386B_5P (plasmid) & HF677575 & 1 & 9914 & 50.75 \\
APA386B_6P (plasmid) & HF677576 & 1 & 6,548 & 51.79 \\
APA386B_7P (plasmid) & HF677577 & 2 & 3851 & 47.03 \\
\hline
\end{tabular}

lagging strands during replication, together with oriC [39]. The occurence of the G/C skew, replichores, and biased distribution of AIMS supports the accuracy of the sequence assembly, as they represent a common general architecture of a genome.

\section{Phylogenetic analysis and comparative genomics}

Synteny analysis revealed a highly conserved order of orthologous genes between the genome sequences of
A. pasteurianus $386 \mathrm{~B}$ and A. pasteurianus IFO 3283 (Figure 2A). The chromosomal synteny was interrupted due to a few transposases/integrases and the presence of genes related to a prophage (Figure 2A). This prophage genomic segment had a size of about $28.8 \mathrm{~kb}$ and comprised 61 genes (APA386B_370 - APA386B_430). Thirteen, six, and six of these genes had homologues in the genomes of A. pasteurianus IFO 3283, Gluconacetobacter diazotrophicus Pal5, and Gluconobacter oxydans $621 \mathrm{H}$, respectively (Additional file 1). The prophage-related region did not contain virulence-associated genes or genes coding for known proteins. However, the region contained an integrase (APA386B_430), a phage terminase (APA386B_403), and a portal protein (APA386B_401), amongst other prophage-related proteins. No head maturation protease, coat protein, or tail measure protein were retrieved, indicating that the prophage is defective [42]. Surprisingly, the genome sequence of A. pasteurianus $386 \mathrm{~B}$ contained only 50 transposases (including plasmids; Additional file 1), none of which was of the IS1380-type, an insertion sequence abundant in multiple $A$. pasteurianus strains $[20,43]$, indicating that the 386B strain is genetically more stable than currently

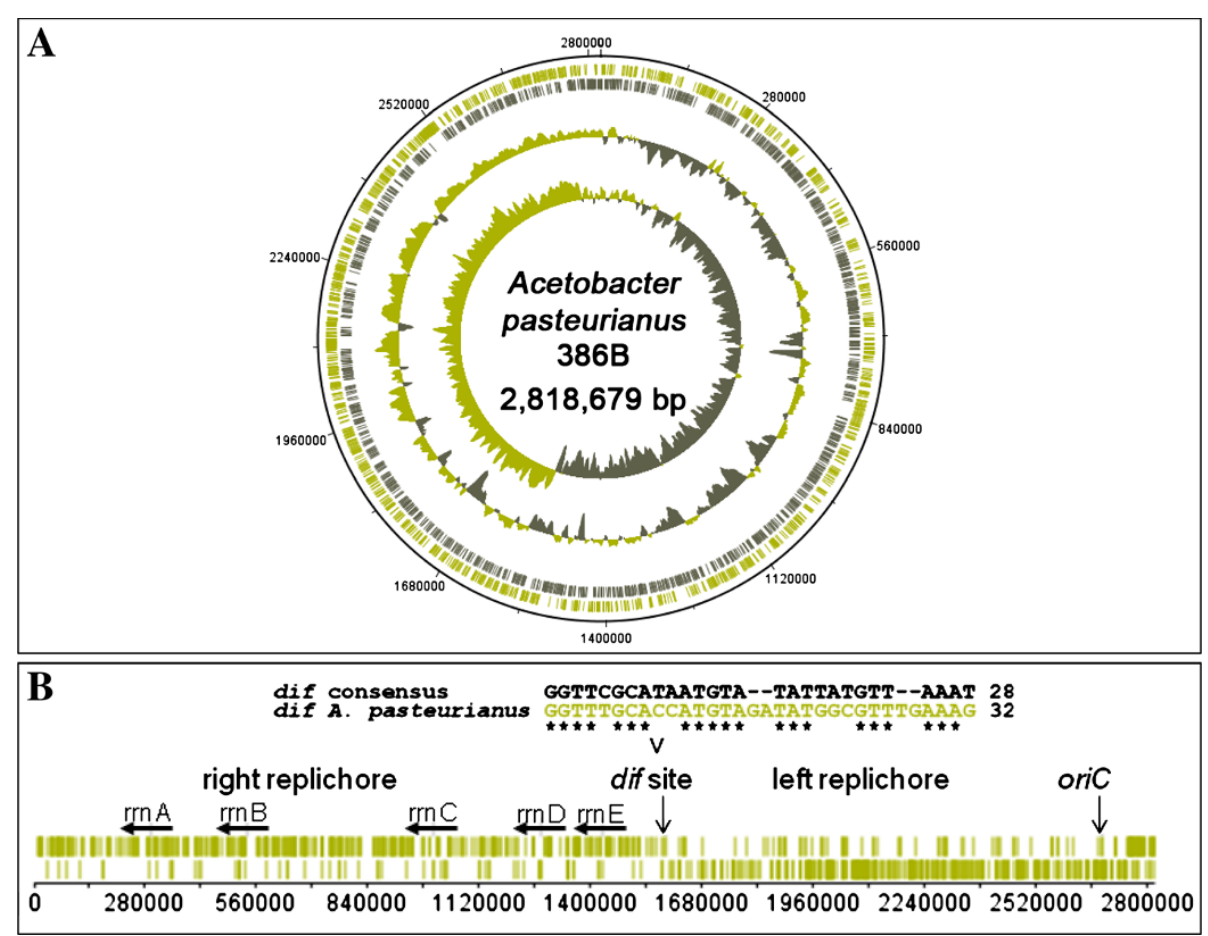

Figure 1 Features of the Acetobacter pasteurianus 386B chromosome. (A) Circular representation of the annotated chromosome of A. pasteurianus 386B. The circles represent (from the outside to the inside): circle 1, DNA base position (bp); circle 2, protein-coding regions transcribed clockwise; circle 3, protein-coding regions transcribed anti-clockwise; circle 4, G+C content plotted using a 10-kb window in steps of 200 bp; circle 5, GC skew plotted using a 10-kb window in steps of 200 bp. (B) Linear representation of the A. pasteurianus 386B chromosome. The occurrence of the architecture imparting sequences (AIMS) is shown (in green) on both strands of the chromosome. These AIMS consist of the octamers [A|C|G]GGGCAGG, GGGCAGG[G|T], GAGCAGGG, GGT|C]GAGGG, and GGG[C|A]AGGG. The origin of chromosomal replication (oriC) as well as the replication termination (dif) site are marked with a vertical arrow. The location of five rRNA operons (rrnA-rrnE) on the leading strand of the A. pasteurianus chromosome is indicated with horizontal black arrows. 
Table 2 Features of the Acetobacter pasteurianus 386B genome

\begin{tabular}{lllllllll}
\hline Feature & Chromosome & Plasmid 1 & Plasmid 2 & Plasmid 3 & Plasmid 4 & Plasmid 5 & Plasmid 6 & Plasmid 7 \\
\hline Total size (bp) & 2818679 & 194780 & 18169 & 15601 & 11105 & 9914 & 6548 & 3851 \\
G+C content (\%) & 52.91 & 52.01 & 55.57 & 55.47 & 52.28 & 50.75 & 51.79 & 47.03 \\
No. of protein-coding genes & 2595 & 220 & 20 & 11 & 9 & 11 & 5 & 4 \\
Coding density (\%) & 89.7 & 82.4 & 72.6 & 61.8 & 73.8 & 58.6 & 34.8 & 90.2 \\
Average gene length (bp) & 975 & 729 & 660 & 876 & 911 & 528 & 456 & 869 \\
No. of rRNA operons & $5 \times 16 S-23 S-5 S$ & 0 & 0 & 0 & 0 & 0 & 0 & 0 \\
No. of tRNAs & 57 & 0 & 0 & 0 & 0 & 0 & 0 & 0 \\
No. of transposases & 26 & 18 & 4 & 0 & 0 & 1 & 0 & 1 \\
\hline
\end{tabular}

known strains of $A$. pasteurianus [20]. In contrast, the genome sequence of $A$. pasteurianus IFO 3283 contains 280 transposons (75 transposases of the IS1380-type), which are involved in the truncation of 32 genes [20]. As these genes, such as a D-galactonate transporter (APA386B_203), an oxalyl-CoA decarboxylase (APA386 B_504), a membrane-bound transporter (APA386B_ 1075), an acetyl-CoA:propanoate CoA-transferase (AP A386B_2066), and an oxidoreductase (APA386B_1P21) were not truncated in $A$. pasteurianus 386B (Additional file 2), they may contribute to specific metabolic features of this strain. For instance, the presence of a functional acetyl-CoA:propanoate CoA-transferase may have implications on metabolic pathways involving acetate, an important substrate in the cocoa bean fermentation.

A comparison of all seven plasmids of $A$. pasteurianus 386B with all six plasmids of $A$. pasteurianus IFO 3283 by means of the ACT and EDGAR software tools demonstrated that both strains did not share the same plasmids, as only very few homologous regions were retrieved (data not shown). For instance, pAPA01-011 and pAPA01-020, the largest plasmids of $A$. pasteurianus IFO 3283, shared
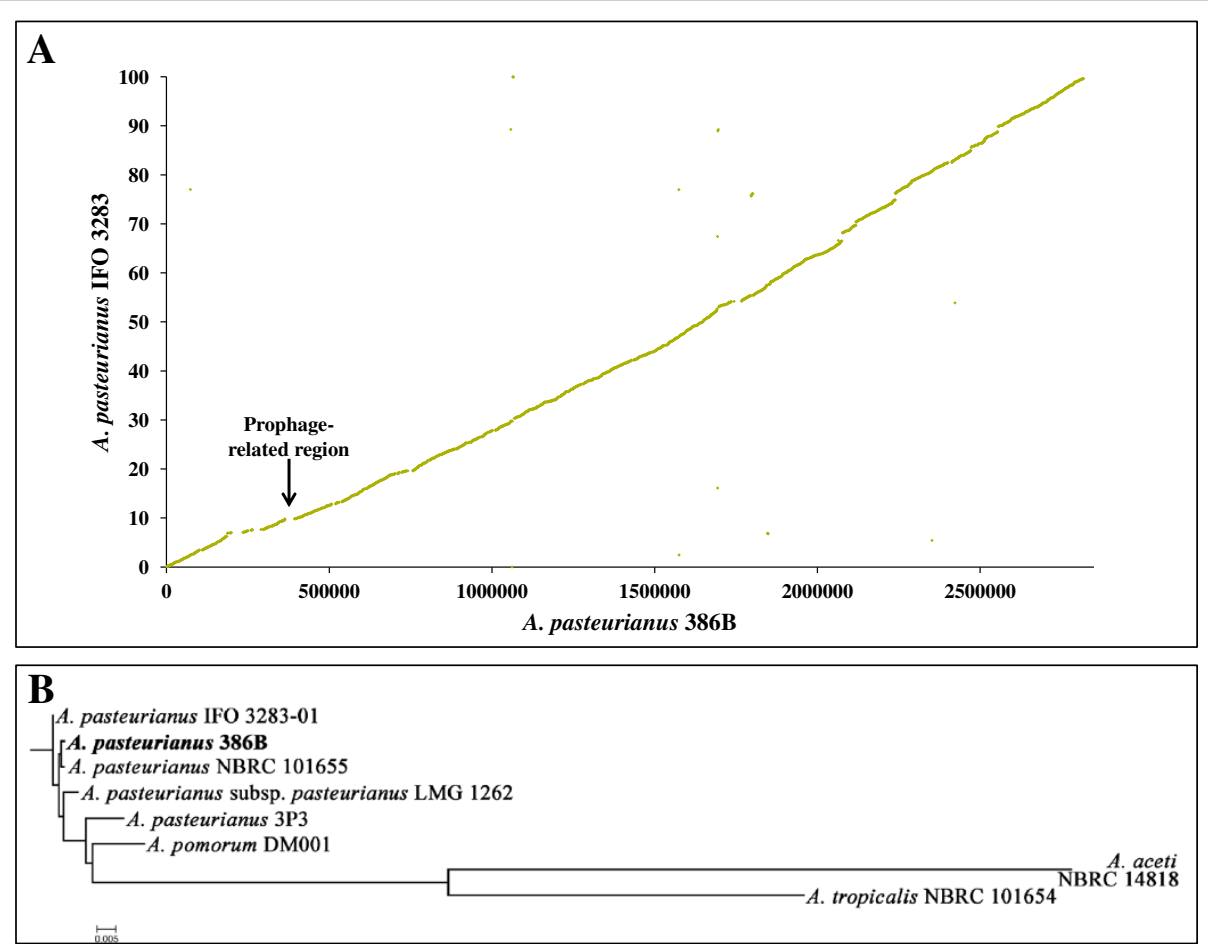

Figure 2 Comparative analysis of the Acetobacter pasteurianus 386B genome. (A) Synteny plot between the chromosomes of $A$. pasteurianus 386B and A. pasteurianus IFO 3283. Each dot represents a predicted A. pasteurianus 386B protein having an ortholog in the $A$. pasteurianus IFO 3283 chromosome, with coordinates corresponding to the position of the respective coding region in each genome. The position of the putative prophage is marked with a vertical black arrow. (B) Phylogenetic tree based on all core genes of the strains included. Multiple sequence alignments of concatenated core gene sequences were calculated within EDGAR. Plasmid sequences were included. 
only 44 and 16 CDS with APA386B_1P, the largest plasmid of A. pasteurianus $386 \mathrm{~B}$, respectively (Figure 3 ). Furthermore, APA386B_1P contained 165 unique genes, not shared with any of the two largest plasmids of $A$. pasteurianus IFO 3283.

Comparative analysis of the five available genome sequences of strains of the species $A$. pasteurianus revealed that there were 2,019 shared orthologous proteins, representing $68 \%$ of the predicted proteins from $A$. pasteurianus $386 \mathrm{~B}$. This may correspond with the core genome of the species Acetobacter pasteurianus. Furthermore, A. pasteurianus 386B contained 122 strain-specific genes, of which 95 had no known function, which may be related with niche adaptations. The 27 unique genes with an assigned function (Additional file 3) may contribute to the performance of this strain as a starter culture in the cocoa bean fermentation process. For instance, the presence of an endopolygalacturonase in the genome sequence of $A$. pasteurianus 386B (APA386B_1663; Additional file 3 ) indicates a possible role of this strain in pectin breakdown, an important metabolic process in the beginning of cocoa bean fermentations $[44,45]$. This is the first report of an endopolygalacturonase gene in an A. pasteurianus strain. Indeed, the closest relative possessing such a gene is A. tropicalis NBRC 101654 [2]; A. tropicalis has been isolated from spontaneous cocoa bean fermentation processes as well [32]. Furthermore, a PCR assay indicated that this polygalacturonase gene was not widespread amongst $A$. pasteurianus strains isolated from spontaneous cocoa bean fermentations (Additional file 4). This suggests that expression of this gene might contribute to the capability of $A$. pasteurianus $386 \mathrm{~B}$ to dominate cocoa bean fermentations.

Phylogenetic analysis of the available genomes of the genus Acetobacter showed that the different Acetobacter pasteurianus strains were clustered together (Figure 2B). Furthermore, $A$. pasteurianus $386 \mathrm{~B}$ was most related to $A$. pasteurianus NBRC 101655, a thermotolerant strain [46,47]. Comparative analysis of $A$. pasteurianus $386 \mathrm{~B}$ in relation to other members of the Acetobacteraceae family revealed that this strain had approximately $20 \%$ shared genes with members of the genus Acidiphilium (Table 3). Furthermore, $27.1 \%$ of the genes are in common with the human pathogen Granulibacter bethesdensis CGDNIH1, whereas members of the genera Gluconobacter and Gluconacetobacter were more closely related to A. pasteurianus 386B, namely 35.6 and $34.5-39.1 \%$ shared genes, respectively. The finding that $A$. pasteurianus $386 \mathrm{~B}$ had more genes in common with Gluconacetobacter species than with G. oxydans $621 \mathrm{H}$ was not in accordance with the phylogenetic relationship based on their complete 16S rRNA gene sequence [48]. This indicates that Gluconacetobacter species are more closely related to Acetobacter species than Gluconobacter species are.

\section{Intracellular metabolism of sugars and sugar derivatives} Acetobacter pasteurianus 386B possessed all genes encoding the enzymes of the Embden-Meyerhof-Parnas (EMP) pathway, except for the phosphofructokinase-coding gene, indicating incomplete glycolysis. The absence of this gene has been reported before in A. pasteurianus IFO 3283, G. diazotrophicus Pal5, and G. oxydans $621 \mathrm{H}$ $[20,25,26]$. However, all genes encoding the enzymes of the pentose-phosphate pathway (PPP) were found (Figure 4), suggesting that glucose is degraded via the PPP, as described previously for $A$. pasteurianus IFO 3283 and $A$. aceti NBRC 14818 [20,23]. Glucose, an important substrate in the cocoa bean fermentation process, could be taken up by sugar permeases (APA386B_1532 and APA386B_2419) or a sugar symporter (APA386B_1333). Fructose-6-phosphate could

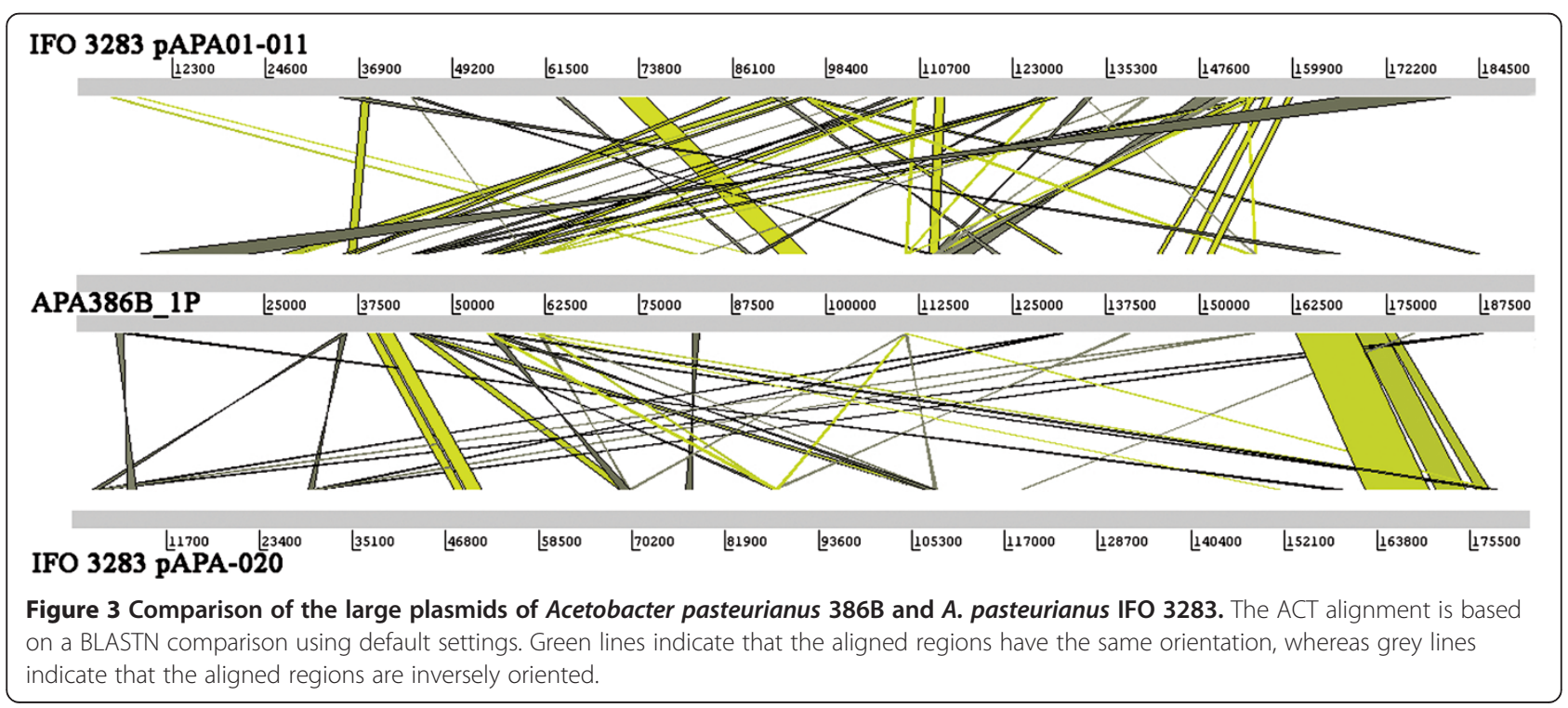


Table 3 Comparative analysis of Acetobacter pasteurianus 386B and members of the Acetobacteraceae family

\begin{tabular}{lll}
\hline Acetic acid bacterium strain & $\begin{array}{l}\text { Number of } \\
\text { shared genes }\end{array}$ & $\begin{array}{l}\text { Percentage of } \\
\text { shared genes }\end{array}$ \\
\hline Acetobacter pasteurianus NBRC 101655 & 2492 & 76.6 \\
Acetobacter pasteurianus IFO 3283 & 2344 & 69.5 \\
Acetobacter pasteurianus LMG 1262 & 2290 & 67.6 \\
Acetobacter pasteurianus 3P3 & 2252 & 66.1 \\
Acetobacter pomorum DM001 & 2067 & 64.7 \\
Acetobacter tropicalis NBRC 101654 & 1980 & 44.8 \\
Acetobacter aceti NBRC 14818 & 1657 & 31.7 \\
Gluconacetobacter diazotrophicus Pal5 & 1603 & 34.5 \\
Gluconacetobacter medellinensis & 1576 & 39.1 \\
NBRC 3288 & & \\
Gluconobacter oxydans 621H & 1383 & 35.6 \\
Granulibacter bethesdensis CGDNIH1 & 1128 & 27.1 \\
Acidiphilium multivorum AlU301 & 1037 & 19.8 \\
Acidiphilium cryptum JF-5 & 1023 & 20.9 \\
\hline
\end{tabular}

Number of shared protein-coding sequences between A. pasteurianus 386B and members of the Acetobacteraceae family for which a complete genome sequence is available. The percentage of shared genes depicts the number of shared genes between two members in relation to the total amount of genes of both members.

be formed from $\mathrm{N}$-acetyl-glucosamine-6-phosphate as well as from mannitol via fructose by a polyol oxidoreductase (APA386B_2545; Figure 4, reaction 52). Fructose6-phosphate could be further metabolized by the EMP pathway (Figure 4). Furthermore, the gene coding for glycerol kinase (glpK; Apa396B_92; Figure 4, reaction 24) was found, allowing the formation of dihydroxyacetone (DHA)-phosphate from glycerol via glycerol 3phosphate, which could be further metabolized by the EMP pathway. DHA-phosphate could be formed by both FAD- and NAD-dependent glycerol 3-phosphate dehydrogenases (APA386B_1931 and APA386B_94; Figure 4, reaction 25). Next to this, the A. pasteurianus 386B genome contained genes coding for a glycerol uptake facilitator protein (APA386B_93), suggesting that this strain is able to take up glycerol from the environment to use it as an energy source, which might be present as a substrate during the cocoa bean fermentation process owing to yeast metabolism. DHAphosphate may be channeled into the lower part of the EMP pathway. The A pasteurianus $386 \mathrm{~B}$ genome sequence provided further evidence that acetate is formed out of ethanol by soluble, $\mathrm{NAD}(\mathrm{P})^{+}$-dependent $\mathrm{ADH}$ (adh; APA386B_1507; Figure 4, reaction 34) and ALDH (APA386B_909; Figure 4, reaction 35) intracellularly, or out of lactate by means of a lactate dehydrogenase $(l d h$; APA386B_910; Figure 4, reaction 29) and pyruvate decarboxylase ( $p d c$; APA386B_1186; Figure 4, reaction 33), as proposed before [49]; F. Moens, T. Lefeber, and
L. De Vuyst, [unpublished observations]. Acetate, formed intracelluarly or available extracellularly, could be further (over)oxidized via acetyl-CoA into carbon dioxide and water by a modified tricarboxylic acid (TCA) cycle, as explained below. Genes encoding enzymes of the glyoxylate pathway were not present. During the course of all aforementioned reactions, $\mathrm{NAD}(\mathrm{P}) \mathrm{H}+\mathrm{H}^{+}$is produced by several dehydrogenases. Indeed, next to the annotated dehydrogenases, the A. pasteurianus 386B genome revealed several putative dehydrogenases/oxidoreductases with a currently unknown function (Additional file 5). These uncharacterized oxidoreductases included four aldehyde dehydrogenases, 15 short-chain dehydrogenases/reductases (involved in oxidation of alcohols to aldehydes), a zinc-binding dehydrogenase, and an oxidoreductase containing a $\mathrm{NAD}^{+}$-binding Rossmann-fold domain. Intracellular dehydrogenase activity is indispensable for the intermediary metabolism of AAB [25].

Genome analysis showed that A. pasteurianus 386B possessed genes encoding metabolic pathways involved in the de novo synthesis of all nucleotides, amino acids, phospholipids and many vitamins, such as biotin, folic acid, pantothenate, pyridoxine, riboflavin, and thiamine. Ammonia, involved in the activity of glutamate synthase (APA386B_893 - APA386B_894) and glutamine synthetase (APA386B_2129), could be taken up by a specific ammonia transporter (APA386B_239). Furthermore, the genome of $A$. pasteurianus $386 \mathrm{~B}$ contained genes to synthesize and use trehalose, which can protect the cell from high osmolarity and/or can be used as an energy source in bacteria and yeast [50]. The pathway consisted of trehalose-6-phosphate synthase (otsA; APA386B_1724), trehalose-6-phosphate phosphatase (otsB; APA386B_17 23), and trehalase (treA; APA386B_104). In addition, genes coding for the mechanosensitive channels MscL (APA3 86B_2572) and MscS (APA386B_1440) were present in the genome sequence of $A$. pasteurianus $386 \mathrm{~B}$, which generally play an important role in osmotolerance [51].

\section{Membrane-bound dehydrogenases and respiratory chain} Acetobacter pasteurianus $386 \mathrm{~B}$ possessed several membrane-bound dehydrogenases that channel electrons into the respiratory chain (Figure 5A). A first group of dehydrogenases depend on the cofactor pyrroloquinoline quinone (PQQ), among which PQQdependent alcohol dehydrogenase (PQQ-ADH) and PQQ-dependent glucose dehydrogenase, allowing the conversion of ethanol into acetaldehyde and glucose into gluconate, respectively, both substrates being available during cocoa bean fermentations. The genes coding for the three subunits of PQQ-ADH were not clustered together in the genome, as the gene encoding the smallest subunit (adhS; APA386B_2212) was separated from the other two genes (adhAB; APA386B_1574 - 


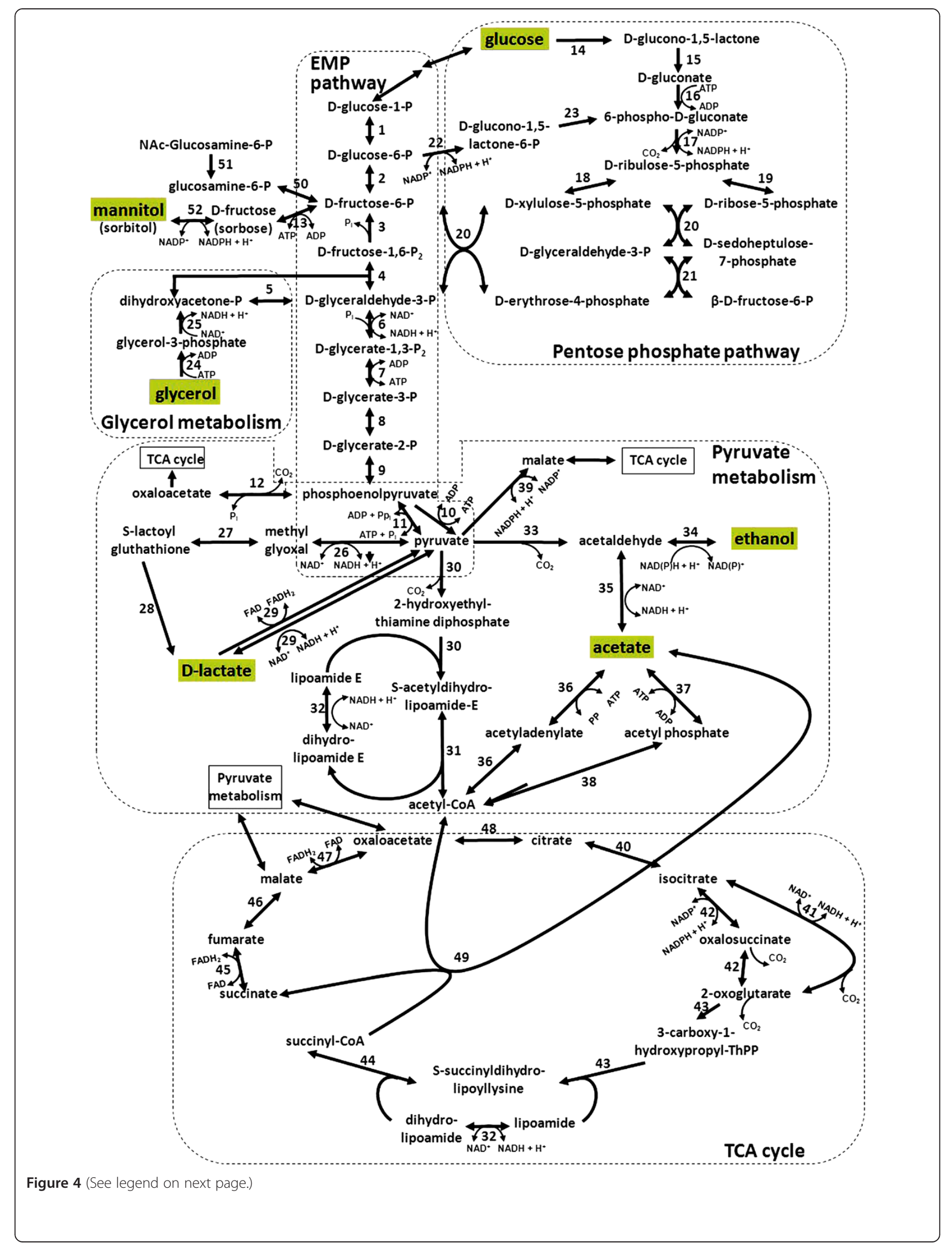


(See figure on previous page.)

Figure 4 Central metabolic pathways of Acetobacter pasteurianus 386B. (1) Phosphoglucomutase (APA386B_513); (2) glucose-6-phosphate isomerase (APA386B_1153); (3) fructose-1,6-biphosphatase I (APA386B_993); (4) fructose-biphosphate aldolase, class I (APA386B_1752); (5) triosephosphate isomerase (APA386B_2746); (6) glyceraldehyde-3-phosphate dehydrogenase (APA386B_1520); (7) phosphoglycerate kinase (APA386B_1519); (8) phosphoglycerate mutase (APA386B_1895 and APA386B_2495); (9) enolase (APA386B_2618); (10) pyruvate kinase (APA386B_2108); (11) pyruvate-phosphate dikinase (APA386B_814); (12) phosphoenolpyruvate carboxylase (APA386B_587); (13) fructokinase (APA386B_356); (14) PQQ-dependent glucose dehydrogenase (APA386B_2133 - APA386B_2134); (15) gluconolactonase (APA386B_2110); (16) gluconate kinase (APA386B_1158); (17) phosphogluconate dehydrogenase (APA386B_1154); (18) ribulose-phosphate 3-epimerase (APA386B_2378); (19) ribose-5-phosphate isomerase A (APA386B_1157); (20) transketolase (APA386B_1152 and APA386B_1521); (21) transaldolase (APA386B_1153) (22) glucose-6-phosphate dehydrogenase (APA386B_729); (23) 6-phosphogluconolactonase (APA386B_1156); (24) glycerol kinase (Apa396B_92); (25) glycerol-3-phosphate dehydrogenase (APA386B_1931 and APA386B_94); (26) pyruvaldehyde oxidoreductase (APA386B_1946); (27) lactoylgluthathione lyase (APA386B_2164 and APA386B_1276); (28) hydroxyacylglutathione hydrolase (APA386B_2280); (29) lactate dehydrogenase (APA386B_910 and APA386B_1053); (30) pyruvate dehydrogenase E1 (APA386B_2083 - APA386B_2084 and APA386B_2737 - APA386B_2738); (31) pyruvate dehydrogenase E2 (APA386B_2085 and APA386B_2736); (32) dihydrolipoamide dehydrogenase (APA386B_2735 and APA386B_2271); (33) pyruvate decarboxylase (APA386B_1186); (34) alcohol dehydrogenase (APA386B_1507, APA386B_2362, and APA386B_496); (35) aldehyde dehydrogenase (APA386B_909); (36) acetyl-CoA synthetase (APA386B_1843 and APA386B_2214); (37) acetate kinase (APA386B_335); (38) phosphate acetyltransferase (APA386B_336); (39) malate dehydrogenase (APA386B_1600); (40) aconitate hydratase 1 (APA386B_1323); (41) NAD+2dependent isocitrate dehydrogenase (APA386B_2558); (42) NADP ${ }^{+}$-dependent isocitrate dehydrogenase (APA386B_2121); (43) 2-oxoglutarate dehydrogenase E1 (APA386B_2269); (44) 2-oxoglutarate dehydrogenase E2 (APA386B_2270); (45) fumarate reductase/succinate dehydrogenase (APA386B_1513 APA386B_1516); (46) fumarate hydratase (APA386B_321 and APA386B_1305); (47) malate:quinone oxidoreductase (APA386B_2675); (48) citrate synthase (APA386B_2584); (49) succinyl-CoA:acetate CoA transferase (APA386B_2589); (50) glucosamine-6-phosphate isomerase (APA386B_546); (51) N-acetylglucosamine-6-phosphate deacetylase (APA386B_1531); (52) polyol oxidoreductase (APA386B_2545).

APA386B_1575). This gene organization in A. pasteurianus has been suggested before [52]. Further, the genome of $A$. pasteurianus 386B contained two uncharacterized, membrane-bound, PQQ-dependent oxidoreductases with five transmembrane helices (Additional file 5). Proteins for the synthesis of the cofactor PQQ are encoded by the pqqABCDE operon (APA386B_983 APA386B_987). In contrast to other AAB, the genome of A. pasteurianus $386 \mathrm{~B}$ did not possess the major polyol dehydrogenase (SldAB), an enzyme of industrial importance [53]. Indeed, SldAB is for instance able to oxidize Dsorbitol into L-sorbose (as part of the production of vitamin $C$ that is used as food supplement and antioxidant), gluconate into 5-ketogluconate (as part of the production of tartaric acid that is used as antioxidant in the food industry), and glycerol into dihydroxyacetone (used in self-tanning creams) $[8,25]$.

A second group of membrane-bound dehydrogenases contains flavines as cofactor. The genes coding for flavine adenine dinucleotide (FAD)-dependent sorbitol dehydrogenase (APA386B_1096 - APA386B_1098) were present in the $A$. pasteurianus $386 \mathrm{~B}$ genome, which points to the ability of this strain to produce fructose from sorbitol. However, it has been shown previously that this dehydrogenase is also responsible for the conversion of mannitol, an important intermediate of the cocoa bean fermentation process, into fructose [54]. As the major polyol dehydrogenase was not present in this strain, it is likely that the FAD-dependent sorbitol dehydrogenase was responsible for the oxidation of mannitol into fructose, as experimentally shown in A. pasteurianus 386B (F. Moens, T. Lefeber, and L. De Vuyst, unpublished observations). In addition, $A$. pasteurianus $386 \mathrm{~B}$ possessed six membranebound oxidoreductases with unknown function (Figure 5B;
Additional file 5). These oxidoreductases are also present in the genomes of $A$. pasteurianus IFO 3283, Ga. diazotrophicus Pal5, and G. oxydans 621H (Additional file 6), and could be involved in the oxidation of a broad range of substrates, such as carbohydrates and polyols [25]. Genome analysis revealed that ubiquinol, generated by the aforementioned membrane-bound dehydrogenases, could be reoxidized by a cytochrome bo3-type ubiquinol oxidase (APA386B_1578 - APA386B_1581) and a cytochrome $b d$-type ubiquinol oxidase (cyanide-insensitive terminal oxidase), whereby the encoding genes of the latter were present twice in the genome sequence of $A$. pasteurianus 386B (cydAB; APA386B_472 - APA386B_ 473 and APA386B_1010 - APA386B_1011). Both terminal oxidases reduce oxygen to water when reoxidizing ubiquinol into ubiquinone (Figure 5B).

The genes coding for a proton-translocating nicotinamide nucleotide transhydrogenase were present in the genome of $A$. pasteurianus 386B (pnt; APA386B_1508 APA386B_1510; Figure 5C). This enzyme might oxidize $\mathrm{NADPH}+\mathrm{H}^{+}$derived from the intermediary metabolism, thereby translocating protons across the cytoplasmic membrane. The $\mathrm{NADH}+\mathrm{H}^{+}$derived from transhydrogenase activity might subsequently be reoxidized by complex I of the respiratory chain, whereas the $\mathrm{NADP}^{+}$derived from the transhydrogenase can be reduced by the $\mathrm{NADP}^{+}$-dependent ALDH [55]. Indeed, the genes coding for a complete proton-translocating respiratory chain complex I were retrieved (пиоA-nиоN; APA386B_556 APA386B_567; Figure 5C). This complex I is absent in G. oxydans, which may be related to its lower growth yields [25]. Furthermore, a membrane-bound succinate dehydrogenase/fumarate reductase was found ( $s d h A B C D$; APA386B_1513 - APA386B_1516; Figure 5C), which is 

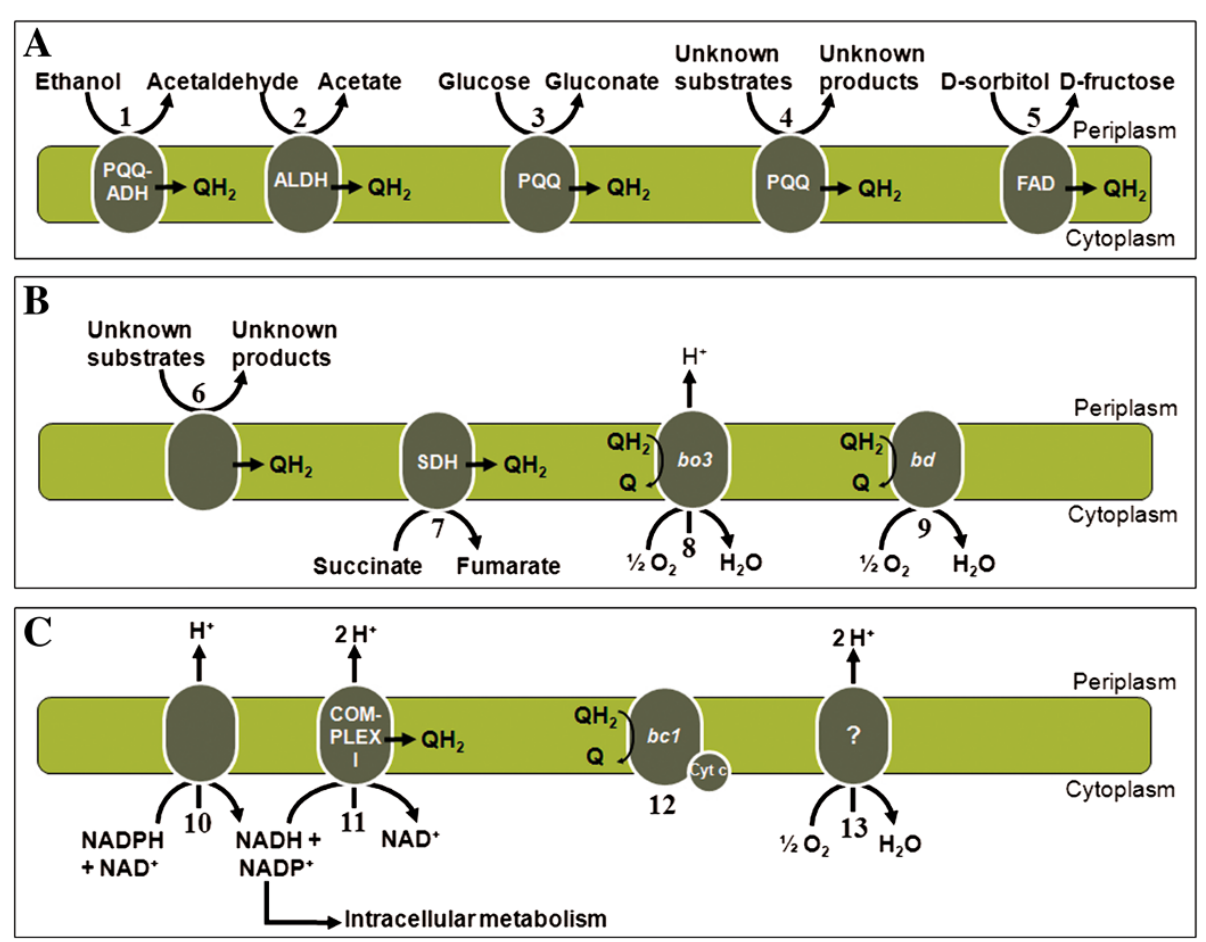

Figure 5 Respiratory chain of Acetobacter pasteurianus 386B. (A) Membrane-bound PQQ- and FAD-dependent dehydrogenases: (1) PQQdependent alcohol dehydrogenase (APA386B_1574 - APA386B_1575); (2) membrane-bound acetaldehyde dehydrogenase (APA386B_2542 APA386B_2544); (3) PQQ-dependent glucose dehydrogenase (APA386B_2133 - APA386B_2134); (4) uncharacterized PQQ-containing oxidoreductases [APA386B_1016 (transmembrane regions: 20-42, 47-64, 69-86, 101-120, 127-149) and APA386B_325 (transmembrane regions: 7-29, 33-55, 64-86, 90-107, 120-142)]; (5) FAD-dependent sorbitol dehydrogenase (APA386B_1096 - APA386B_1098). (B) Membrane-bound oxidoreductases and terminal oxidases: (6) uncharacterized oxidoreductases [APA386B_1815 (transmembrane region: 133-153), APA386B_1888 (transmembrane region: 307-329), APA386B_2052 (transmembrane region: 9-31), APA386B_767 (transmembrane region: 36-102), APA386B_1507 (transmembrane region: 168-188), and APA386B_2362 (transmembrane regions: 164-184, 222-242)]; (7) succinate dehydrogenase/fumarate reductase (APA386B_1513 - APA386B_1516); (8) cytochrome bo 3 ubiquinol oxidase (APA386B_1578 - APA386B_1581); (9) cytochrome bd ubiquinol oxidase (APA386B_472 - APA386B_473 and APA386B_1010-APA386B_1011). (C) Respiratory chain core system: (10) proton-translocating transhydrogenase (APA386B_1508 - APA386B_1510); (11) proton-translocating NADH:ubiquinone oxidoreductase (complex I; APA386B_556 APA386B_567 and APA386B_2247); (12) bc, complex ubiquinol:cytochrome c oxidoreductase (complex III; APA386B_775 - APA386B_777); (13) incomplete cytochrome c oxidase (APA386B_609). Cyt c: cytochrome c (APA386B_367 and APA386B_906).

not only part of the respiratory chain, but also plays an important role in the TCA cycle, thereby enabling overoxidation of acetic acid [56]. Genes encoding both a $b c_{1}$ complex (ubiquinol:cytochrome $c$ oxidoreductase; petABC; APA386B_775 - APA386B_777) as well as cytochrome $c$ (cytC; APA386B_367 and APA386B_906) were identified in the genome of A. pasteurianus 386B. Furthermore, genes for the transport of heme $\mathrm{c}$ and the maturation of cytochrome $c$ were present (ccmFGHI; APA386B_2396 - APA386B_2400) [57]. However, it is unknown if this strain is able to reoxidize the reduced form of cytochrome $c$, as cytochrome $c$ oxidase (complex IV) is probably inactive, because only subunit I (APA386B_609) was present in the genome.

In silico analysis of mechanisms involved in acid tolerance A first strategy of $A$. pasteurianus $386 \mathrm{~B}$ to tolerate high levels of acetic acid may consist of a cytosolic acetate- assimilating detoxification pathway. This involves a conversion of acetate to acetyl-CoA, which is performed either by acetyl-CoA synthetase (acn; APA386B_2214 and APA386B_1843; Figure 4, reaction 36) or by acetate kinase (ackA; APA386B_335; Figure 4, reaction 37) and phosphate acetyltransferase (pta; APA386B_336; Figure 4, reaction 38). Both pathways were present in the $A$. pasteurianus $386 \mathrm{~B}$ genome and are known to be upregulated when citrate oxidation takes place [58]. This suggests that the presence of two copies of the acn gene in this strain provides an advantage for efficient acetate assimilation. Alternatively, acetate can be converted into acetyl-CoA via a modified TCA cycle [59]. Indeed, all genes encoding the enzymes of the TCA cycle were retrieved, except for succinyl-CoA synthetase. This function is bypassed by succinyl-CoA: acetate CoA transferase (SCACT, aarC; APA386B_2589; Figure 4 , reaction 50). Similarly, the gene for malate 
dehydrogenase was not found, but oxidation of malate into oxaloacetate can be catalyzed by malate:quinone oxidoreductase (mqo; APA386B_2675; Figure 4, reaction 48) [59]. A second mechanism in acid tolerance probably involves the presence of an acetic acid resistance ABC transporter (aatA; APA386B_103), an efflux pump in the cytoplasmic membrane capable of exporting acetic acid [60]. Thirdly, A. pasteurianus 386B contained the gene cluster involved in pellicle polysaccharide formation (polABCDE; APA386B_1394 APA386B_1398), preventing the diffusion of acetic acid into the cytoplasm $[46,61,62]$. Fourthly, the genes coding for urease (ureDABCEFG; APA386B_1179 - A PA386B_1184), an urea transporter (urt $A B C D E$; AP A386B_1640 - APA386B_1644), an allophanate hydrolase (APA386B_936 - APA386B_937), and an urea carboxylase (APA386B_218) were present, indicating the ability to transport urea and convert it into ammonia, which may contribute to the survival of $A$. pasteurianus $386 \mathrm{~B}$ in acidic environments, such as the cocoa pulp-bean mass ( $\mathrm{pH} 3.5$ - 4.5). The human pathogenic Gr. bethesdensis CGDNIH1 contains this mechanism too, although it may not be widespread among $\mathrm{AAB}$ strains, as it is absent in G. oxydans $621 \mathrm{H}$ and $\mathrm{Ga}$. diazotrophicus Pal5 [25,26,63]. Lastly, genome analysis of $A$. pasteurianus 386B revealed the presence of genes coding for cytoplasmic components that are adapted to intracellular acidification. This is the case for $N^{5}$-carboxyaminoimidazole ribonucleotide $\left(N^{5}\right.$-CAIR) mutase (purE; APA386B_2565), a protein involved in purine biosynthesis. Indeed, $N^{5}$-CAIR mutase of $A$. pasteurianus $386 \mathrm{~B}$ is $99 \%$ identical to its orthologue in $A$. aceti 1023 , the latter strain being adapted to an acid cytosol [64]. Similarly, alanine racemase (alr; APA386B_1310), a protein involved in peptidoglycan biosynthesis, is $92 \%$ identical to the $A$. aceti 1023 orthologue, a protein known to function at low $\mathrm{pH}$ [65]. In addition, the sequence similarity of both $N^{5}$-CAIR mutase and alanine racemase between $A$. pasteurianus 386B and $A$. aceti 1023 was higher than between A. pasteurianus $386 \mathrm{~B}$ and any other sequenced $\mathrm{AAB}$ strain (data not shown), indicating that the presence of acidstable proteins is not widespread.

\section{In silico analysis of mechanisms involved in thermotolerance}

As described above, genome-wide phylogenetic analysis of A. pasteurianus $386 \mathrm{~B}$ revealed that this strain is most related to the thermotolerant strain $A$. pasteurianus NBRC 101655 . In addition, adaptive mutation resulted in 14 validated mutations, involved in improved thermotolerance of this strain [66]. Five of these regions were also modified in A. pasteurianus $386 \mathrm{~B}$ and not in $A$. pasteurianus NBRC 101655 (Additional file 7). For example, one of the two genes coding for cytochrome $c$ (APA386B_906), contained three synonymous mutations and one nonsynonymous mutation. Furthermore, the genes necessary for growth at high temperatures $\left(42^{\circ} \mathrm{C}\right)$ of the thermotolerant strain $A$. tropicalis NBRC 101654 have been identified recently [4]. Although this strain belongs to a different species than A. pasteurianus $386 \mathrm{~B}$, all genes of $A$. tropicalis NBRC 101654 necessary for growth at high temperatures were found in the genome sequence of $A$. pasteurianus 386B as well (Additional file 7). This indicates that the latter strain, when thriving in the high-temperature cocoa pulp-bean mass, may use the same mechanisms towards heat stress as A. tropicalis NBRC 101654.

\section{Conclusions}

The complete genome sequence of $A$. pasteurianus 386B, a strain originating from a spontaneous cocoa bean heap fermentation in Ghana, was determined, annotated, and described in this study. The global overview of all genes and pathways obtained provided comprehensive insights into the metabolic features regarding important substrates (such as ethanol, glucose, acetate, lactate, and glycerol) and stresses (such as acidic and heat stress) during the cocoa bean fermentation process.

Comparative genome analysis provided information regarding niche adaptations of this strain. For example, the presence of a gene coding for an endopolygalacturonase was discovered. This enzyme is involved in the breakdown of pectin, a compound responsible for the viscosity of the cocoa pulp-bean mass. Although depectinization is mainly important in the beginning (anaerobic yeast activity phase) of the cocoa bean fermentation process, the activity of the pectinolytic enzymes allows air to enter the cocoa pulpbean mass, which promotes the growth of obligate aerobic $A A B$. Therefore, the presence of this gene could be an important prerequisite for survival and performance of $\mathrm{AAB}$ during cocoa bean fermentations. Furthermore, the comparative genome analysis revealed that the genome of $A$. pasteurianus $386 \mathrm{~B}$ contained a low number of transposases, resulting in the absence of truncated genes, which might be important for expression under cocoa bean fermentation conditions.

Genome analysis unraveled various mechanisms of $A$. pasteurianus $386 \mathrm{~B}$ to tolerate stress conditions occurring in a cocoa bean fermentation ecosystem. As also active prophages were absent in the genome sequence, these findings indicate that $A$. pasteurianus $386 \mathrm{~B}$ is genetically more stable compared with other fully characterized $\mathrm{AAB}$, contributing to the prerequisites of a starter culture strain.

All these findings support that this strain is a suitable functional starter culture for controlled cocoa bean fermentation processes. In addition, the results presented in this study will enable analysis of the transcriptome of A. pasteurianus $386 \mathrm{~B}$, which will provide insight into its metabolic activity. Finally, the characteristics of $A$. 
pasteurianus $386 \mathrm{~B}$ revealed in this study are essential to generate further insights into the functional role of $\mathrm{AAB}$ in general, and A. pasteurianus in particular, during the cocoa bean fermentation process, which is of great importance to select an appropriate starter culture for homogeneous, fast, and successfully controlled fermentation processes.

\section{Methods}

\section{Bacterial strain and growth conditions}

Acetobacter pasteurianus 386B was originally isolated from a spontaneous cocoa bean heap fermentation carried out in Ghana [18]. The strain was stored at $-80^{\circ} \mathrm{C}$ in mannitol-yeast extract-peptone (MYP) medium [2.5\% D-mannitol, $0.5 \%$ yeast extract, and $0.3 \%$ bacteriological peptone (Oxoid, Basingstoke, Hampshire, United Kingdom), $\mathrm{w} / \mathrm{v}$ ], supplemented with $25 \%(\mathrm{v} / \mathrm{v})$ glycerol as a cryoprotectant. To obtain cell pellets, A. pasteurianus 386B was propagated in MYP medium twice (aerobic incubation at $30^{\circ} \mathrm{C}$ overnight), followed by centrifugation $(21,036 \times g$, $15 \mathrm{~min}, 4^{\circ} \mathrm{C}$ ) of 2 -ml cultures.

\section{DNA extraction and $\mathbf{4 5 4}$ pyrosequencing}

Total genomic DNA was extracted from cell pellets using the High Pure PCR Template Preparation Kit (Roche Applied Science, Mannheim, Germany), followed by RNase treatment and purification using the High Pure PCR Product Purification Kit (Roche Applied Science), always according to the manufacturer's instructions. To confirm the identity of the bacterial strain grown, a $16 \mathrm{~S}$ rRNA gene-specific region was amplified based on the genomic DNA extracted, as described previously [67]. Amplicons were purified using the Wizard SV Gel and PCR Clean up system (Promega, Madison, WI, USA) and sequenced at a commercial facility using Sanger sequencing (VIB Genetic Service Facility, Antwerp, Belgium). The quality of the genomic DNA was assessed by gel electrophoresis; its quantity was estimated by a fluorescence-based method using the Quant-iT dsDNA Assay kit (Invitrogen, Carlsbad, CA, USA) and the DTX800 multimode detector (Beckman Coulter, Pasadena, CA, USA).

For genome sequencing, a total amount of $5 \mu \mathrm{g}$ of genomic DNA was used for the construction of an $8-\mathrm{kb}$ paired-end library with the GS FLX Titanium Library Paired-End Adaptors Kit and the GS FLX Titanium Rapid Library Prep Kit (Roche Applied Science) according to the manufacturer's instructions. The optimal DNA copy per bead ratio was determined by an emulsion PCR titration using a GS FLX Titanium SV emPCR kit (Lib-L) (Roche Applied Science). The final emulsion PCR was performed using the GS FLX Titanium LV emPCR kit (Lib-L; Roche Applied Science). Pyrosequencing was performed on a Genome Sequencer GS FLX instrument using Titanium chemistry (Roche Applied Science) with the sample occupying one region of a four-region gasket. Library preparation and pyrosequencing were performed by the VIB Nucleomics Core Facility (Leuven, Belgium). Reads were assembled using the GS De Novo Assembler version 2.5.3 with default parameters.

\section{PCR-based gap closure}

To close remaining gaps in the assembled genome sequence, PCR primers were designed based on contig ends using the Consed program [68] and synthesized in a commercial facility (Integrated DNA Technologies, Leuven, Belgium). PCR assays were performed using a DNA T3000 thermocycler (Biometra, Goettingen, Germany), containing $50 \mathrm{ng}$ of genomic DNA, $100 \mu \mathrm{M}$ of each dNTP (Sigma-Aldrich, St. Louis, MO, USA), 5 pmole of each primer, $5 \mu \mathrm{L}$ of $10 \times$ PCR reaction buffer (Fermentas, St. Leon-Rot, Germany), $1.875 \mathrm{U}$ of Pfu DNA Polymerase (Fermentas), and sterile ultrapure water in a final volume of $50 \mu \mathrm{L}$. Following amplification, PCR product sizes were verified using a 1.0-\% (w/v) agarose gel and the remaining reaction mixture was purified using the Wizard SV Gel and PCR Clean up system (Promega). Amplicons were sequenced in a commercial facility using Sanger sequencing technology (Macrogen Europe, Amsterdam, The Netherlands). All DNA sequences obtained were uploaded into the Consed program, manually inspected, and integrated into the genome assembly to generate the complete genome sequence of $A$. pasteurianus 386B. To facilitate gap closure and assembly validation, contigs were mapped to the A. pasteurianus IFO 3283 genome by means of the r2cat tool $[20,69]$.

\section{Genome analysis and annotation}

Automatic gene prediction and annotation of the assembled genome sequence were carried out using a local installation of the bacterial genome annotation system GenDB v2.2 [70]. A combined gene prediction strategy was applied by using GLIMMER 2.1 and the CRITICA program suite [71,72]. Putative ribosomal binding sites and tRNA genes were identified with the RBSfinder tool [73] and tRNAscan-SE [74]. The deduced proteins were functionally characterized by REGANOR [75] using automated searches in public databases, including SWISS-PROT and TrEMBL [76], Pfam [77], KEGG [78], and TIGRFAM [79]. Additionally, SignalP (detection of signal peptides) [80], helix-turn-helix (identification of helix-turn-helix DNA binding motifs) [81], and TMHMM (detection of transmembrane regions) [82] were applied. Each gene was functionally classified by assigning a Cluster of Orthologous groups (COG) number [83] and a Gene Ontology (GO) number [84]. The automated gene prediction and annotation was followed by manual curation of the data. To correct for over-annotation, 
short CDS without functional annotation, with low confidence scores inferred by the GenDB platform, and with overlaps with other CDS were eliminated from the final annotation. A genome plot of A pasteurianus 386B was generated with the DNAPlotter tool [85]. The origin of chromosomal replication of $A$. pasteurianus 386B was predicted with the Ori-Finder tool [40]. CRISPRs were searched for with the CRISPRFinder tool [86].

\section{Phylogenetic analysis and comparative genomics}

A phylogenetic analysis was performed using complete and draft genome sequences of members of the family Acetobacteraceae. Therefore, the annotated genome sequences of the finished genomes of $A$. pasteurianus IFO 3283 (including plasmids), Acidiphilium multivorum AIU301, Acidiphilium cryptum JF-5, Ga. diazotrophicus Pal5, Ga. medellinensis NBRC 3288 (formerly Gluconacetobacter xylinus NBRC 3288), and G. oxydans $621 \mathrm{H}$ were used $[25-27,63,87]$. Furthermore, the draft genome sequences (contigs and scaffolds) of $A$. pasteurianus subsp. pasteurianus LMG $1262^{\mathrm{T}}$, A. pasteurianus NBRC 101655, A. pomorum DM001, A. tropicalis NBRC 101654, and $A$. aceti NBRC 14818 were included $[2,5,20,22,23]$. As no annotation of the draft genome sequence of $A$. pasteurianus 3P3 [21] was available, the draft genome was annotated using the GenDB platform as described above. The manually curated genome sequence of $A$. pasteurianus 386B, together with the plasmids identified, was incorporated as well. Comparative analysis of these genome sequences, including synteny analyses, identification and classification of orthologous genes, and phylogenetic analysis was accomplished by the EDGAR software framework using default parameters [88]. In addition, the Artemis Comparison Tool (ACT) was applied to identify similarity between the different plasmids of $A$. pasteurianus $386 \mathrm{~B}$ and A. pasteurianus IFO 3283 [89], using the BLASTN algorithm with default parameters [90].

\section{Data availability}

The annotated sequences of the A. pasteurianus chromosome and plasmids were deposited in the DDBJ/EMBL/ GenBank database (Sequencing Project PRJEB1172). The accession numbers are listed in Table 1.

\section{Additional files}

Additional file 1: Prophage- and transposon-related genes of Acetobacter pasteurianus 386B. Homologues of the genes involved are shown for A. pasteurianus IFO 3283, Ga. diazotrophicus Pal5, and G. oxydans $621 \mathrm{H}$.

Additional file 2: Overview of genes in Acetobacter pasteurianus 386B truncated by transposons in A. pasteurianus IFO 3283.

Overview of genomic positions of the homologues of truncated gene fragments of A. pasteurianus IFO 3283 in A. pasteurianus 386B.
Additional file 3: Strain-specific genes of Acetobacter pasteurianus 386B. Unique genes were identified by comparative analysis of five available genome sequences of $A$. pasteurianus strains using EDGAR.

Additional file 4: PCR assay for endopolygalacturonase gene. Assays were performed on selected A. pasteurianus strains, originating from spontaneous cocoa bean fermentations.

Additional file 5: Uncharacterized oxidoreductases of Acetobacter pasteurianus 386B. Features of the genes that could be annotated are listed. The oxidoreductases are classified according to their protein family.

Additional file 6: Genes of Acetobacter pasteurianus 386B coding for membrane-bound oxidoreductases with unknown specific function. Homologues of the genes involved are shown for $A$. pasteurianus IFO 3283, Ga. diazotrophicus Pal5, and G. oxydans $621 \mathrm{H}$.

Additional file 7: Genes of Acetobacter pasteurianus 386B involved in thermotolerance. List of homologous genes between A. pasteurianus 386B and A. tropicalis NBRC 101654, and between A. pasteurianus 386B and A. pasteurianus NBRC 101655.

\section{Abbreviations}

AAB: Acetic acid bacteria; ACT: Artemis comparison tool; ADH: Alcohol dehydrogenase; AIMS: Architecture imparting sequences; ALDH: Aldehyde dehydrogenase; CDS: Protein-coding sequences; COG: Cluster of orthologous groups; CPSM: Cocoa pulp simulation medium; CRISPR: Clustered regularly interspaced short palindromic repeat; DHA: Dihydroxyacetone;

EMP: Embden-Meyerhof-Parnas; FAD: Flavine adenine dinucleotide; GO: Gene ontology; LAB: Lactic acid bacteria; MYP: Mannitol-yeast extract-peptone; $N^{5}$-CAIR: $N^{5}$-carboxyaminoimidazole ribonucleotide; PPP: Pentose-phosphate pathway; PQQ: Pyrroloquinoline quinone; SCACT: Succinyl-CoA:acetate COA transferase; TCA: Tricarboxylic acid

\section{Competing interests}

The authors declare that they have no competing interests.

\section{Authors' contributions}

$\mathrm{KI}$ carried out DNA extraction, conducted genome assembly and finishing, performed sequence annotation, bioinformatics analyses, and comparative genome analyses. SW and LDV designed and coordinated the study and participated in the analysis of the results. KI, SW, and LDV wrote the manuscript. All authors read and approved the final manuscript.

\section{Acknowledgements}

We thank Dipl.-Inform. Jochen Blom and Dr. Alexander Goesmann [Bioinformatics Resource Facility, Center for Biotechnology (CeBiTec), Bielefeld University, Germany] for performing the EDGAR computational analysis and assistance with the installation of the GenDB platform, respectively. This research was financed by the Research Council of the Vrije Universiteit Brussel and the Research Foundation Flanders (FWO; project number 1.5.108.09N). $\mathrm{Kl}$ is the receiver of a post-graduate grant of the Agency for Innovation by Science and Technology (IWT). The funders had no role in the design of the study, the collection and analysis of the data, the writing of the manuscript, or the decision to submit the manuscript for publication.

Received: 18 February 2013 Accepted: 27 July 2013

Published: 1 August 2013

\section{References}

1. Kersters K, Lisdiyanti P, Komagata K, Swings J: The family Acetobacteraceae: the genera Acetobacter, Acidomonas, Asaia, Gluconacetobacter, Gluconobacter, and Kozakia. In The Prokaryotes. Edited by Dworkin M, Falkow S, Rosenberg E, Schleifer K-H, Stackebrandt E. New York: Springer; 2006:163-200.

2. Matsutani M, Hirakawa H, Nishikura M, Soemphol W, Ali IAl, Yakushi T, Matsushita K: Increased number of arginine-based salt bridges contributes to the thermotolerance of thermotolerant acetic acid bacteria, Acetobacter tropicalis SKU1100. Biochem Biophys Res Commun 2011, 409:120-124

3. Sengun IY, Karabiyikli S: Importance of acetic acid bacteria in food industry. Food Control 2011, 22:647-656. 
4. Soemphol W, Deeraksa A, Matsutani M, Yakushi T, Toyama H, Adachi O, Yamada M, Matsushita K: Global analysis of the genes involved in the thermotolerance mechanism of thermotolerant Acetobacter tropicalis SKU1100. Biosci Biotechnol Biochem 2011, 75:1921-1928.

5. Shin SC, Kim S-H, You H, Kim B, Kim AC, Lee K-A, Yoon J-H, Ryu J-H, Lee W-J: Drosophila microbiome modulates host developmental and metabolic homeostasis via insulin signaling. Science 2011, 334:670-674.

6. De Vuyst L, Lefeber T, Papalexandratou Z, Camu N: The functional role of lactic acid bacteria in cocoa bean fermentation. In Biotechnology of Lactic Acid Bacteria: Novel Applications. Edited by Mozzi F, Raya RR, Vignolo GM. Oxford, UK: Wiley-Blackwel; 2010:301-325.

7. Adachi O, Moonmangmee D, Toyama H, Yamada M, Shinagawa E, Matsushita K: New developments in oxidative fermentation. Appl Microbiol Biotechnol 2003, 60:643-653.

8. Raspor P, Goranovic D: Biotechnological applications of acetic acid bacteria. Crit Rev Biotechnol 2008, 28:101-124.

9. Bremus $\mathrm{C}$, Herrmann U, Bringer-Meyer $\mathrm{S}$, Sahm H: The use of microorganisms in L-ascorbic acid production. J Biotechnol 2006, 124:196-205.

10. Römling U: Molecular biology of cellulose production in bacteria. Res Microbiol 2002, 153:205-212.

11. Matsushita K, Toyama H, Adachi O: Respiratory chains and bioenergetics of acetic acid bacteria. Adv Microb Physiol 1994, 36:247-301.

12. González Á, Mas A: Differentiation of acetic acid bacteria based on sequence analysis of 16S-23S rRNA gene internal transcribed spacer sequences. Int J Food Microbiol 2011, 147:217-222.

13. Matsutani M, Hirakawa H, Yakushi T, Matsushita K: Genome-wide phylogenetic analysis of Gluconobacter, Acetobacter, and Gluconacetobacter. FEMS Microbiol Lett 2010, 315:122-128.

14. Zahoor $T$, Siddique $F$, Farooq U: Isolation and characterization of vinegar culture (Acetobacter aceti) from indigenous sources. Br Food J 2006, 108:429-439.

15. Sokollek SJ, Hertel C, Hammes WP: Description of Acetobacter oboediens sp. nov. and Acetobacter pomorum sp. nov., two new species isolated from industrial vinegar fermentations. Int J Syst Bacteriol 1998, 48:935-940.

16. Cleenwerck I, Vandemeulebroecke K, Janssens D, Swings J: Re-examination of the genus Acetobacter, with descriptions of Acetobacter cerevisiae sp. nov. and Acetobacter malorum sp. nov. Int J Syst Evol Microbiol 2002, 52:1551-1558.

17. Prieto C, Jara C, Mas A, Romero J: Application of molecular methods for analysing the distribution and diversity of acetic acid bacteria in Chilean vineyards. Int J Food Microbiol 2007, 115:348-355.

18. Camu N, De Winter T, Verbrugghe K, Cleenwerck I, Vandamme P, Takrama JS, Vancanneyt M, De Vuyst L: Dynamics and biodiversity of populations of lactic acid bacteria and acetic acid bacteria involved in spontaneous heap fermentation of cocoa beans in Ghana. Appl Environ Microbiol 2007 73:1809-1824.

19. Yamada $Y$, Hoshino K-i, Ishikawa T: The phylogeny of acetic acid bacteria based on the partial sequences of $16 \mathrm{~S}$ ribosomal RNA: the elevation of the subgenus Gluconoacetobacter to the generic level. Biosci Biotechnol Biochem 1997, 61:1244-1251.

20. Azuma Y, Hosoyama A, Matsutani M, Furuya N, Horikawa H, Harada T, Hirakawa H, Kuhara S, Matsushita K, Fujita N, Shirai M: Whole-genome analyses reveal genetic instability of Acetobacter pasteurianus. Nucleic Acids Res 2009, 37:5768-5783.

21. Andrés-Barrao C, Falquet L, Calderon-Copete SP, Descombes P, Ortega Pérez $R$, Barja F: Genome sequences of the high-acetic acid-resistant bacteria Gluconacetobacter europaeus LMG $18890^{\top}$ and G. europaeus LMG 18494 (reference strains), G. europaeus 5P3, and Gluconacetobacter oboediens 174Bp2 (isolated from vinegar). J Bacterio/ 2011, 193:2670-2671.

22. Matsutani M, Hirakawa H, Saichana N, Soemphol W, Yakushi T, Matsushita K: Genome-wide phylogenetic analysis of differences in thermotolerance among closely related Acetobacter pasteurianus strains. Microbiology 2012, 158:229-239.

23. Sakurai $\mathrm{K}$, Arai $\mathrm{H}$, Ishii $\mathrm{M}$, Igarashi $\mathrm{Y}$ : Transcriptome response to different carbon sources in Acetobacter aceti. Microbiology 2010, 157:899-910.

24. Lisdiyanti P, Katsura K, Potacharoen W, Navarro RR, Yamada Y, Uchimura T, Komagata K: Diversity of acetic acid bacteria in Indonesia, Thailand, and the Philippines. Microbiol Cult Coll 2003, 19:91-98.

25. Prust C, Hoffmeister M, Liesegang H, Wiezer A, Fricke WF, Ehrenreich A Gottschalk G, Deppenmeier U: Complete genome sequence of the acetic acid bacterium Gluconobacter oxydans. Nat Biotechnol 2005, 23:195-200.

26. Bertalan M, Albano R, de Padua V, Rouws L, Rojas C, Hemerly A, Teixeira K, Schwab S, Araujo J, Oliveira A, Franca L, Magalhaes V, Alqueres S, Cardoso A,
Almeida W, Loureiro M, Nogueira E, Cidade D, Oliveira D, Simao T, Macedo J, Valadao A, Dreschsel M, Freitas F, Vidal M, Guedes H, Rodrigues E, Meneses C, Brioso P, Pozzer L: Complete genome sequence of the sugarcane nitrogen-fixing endophyte Gluconacetobacter diazotrophicus Pal5. BMC Genomics 2009, 10:450

27. Ogino H, Azuma Y, Hosoyama A, Nakazawa H, Matsutani M, Hasegawa A Otsuyama K-i, Matsushita K, Fujita N, Shirai M: Complete genome sequence of NBRC 3288, a unique cellulose-nonproducing strain of Gluconacetobacter xylinus isolated from vinegar. J Bacteriol 2011, 193:6997-6998.

28. Vegas C, Mateo E, González Á, Jara C, Guillamón JM, Poblet M, Torija MJ, Mas A: Population dynamics of acetic acid bacteria during traditional wine vinegar production. Int J Food Microbiol 2010, 138:130-136.

29. Gullo M, Caggia C, De Vero L, Giudici P: Characterization of acetic acid bacteria in 'traditional balsamic vinegar'. Int J Food Microbiol 2006, 106:209-212.

30. Haruta S, Ueno S, Egawa I, Hashiguchi K, Fujii A, Nagano M, Ishii M, Igarashi Y: Succession of bacterial and fungal communities during a traditional pot fermentation of rice vinegar assessed by PCRmediated denaturing gradient gel electrophoresis. Int J Food Microbiol 2006, 109:79-87.

31. Papalexandratou Z, Vrancken G, De Bruyne K, Vandamme P, De Vuyst L: Spontaneous organic cocoa bean box fermentations in Brazil are characterized by a restricted species diversity of lactic acid bacteria and acetic acid bacteria. Food Microbiol 2011, 28:1326-1338.

32. Nielsen DS, Teniola OD, Ban-Koffi L, Owusu M, Andersson TS, Holzapfel WH: The microbiology of Ghanaian cocoa fermentations analysed using culture-dependent and culture-independent methods. Int J Food Microbiol 2007, 114:168-186.

33. Illeghems K, De Vuyst L, Papalexandratou Z, Weckx S: Phylogenetic analysis of a spontaneous cocoa bean fermentation metagenome reveals new insights into its bacterial and fungal community diversity. PLoS One 2012, 7:e38040.

34. Schwan RF, Wheals AE: The microbiology of cocoa fermentation and its role in chocolate quality. Crit Rev Food Sci Nutr 2004, 44:205-221.

35. Lefeber T, Janssens M, Moens F, Gobert W, De Vuyst L: Interesting starter culture strains for controlled cocoa bean fermentation revealed by simulated cocoa pulp fermentations of cocoa-specific lactic acid bacteria. Appl Environ Microbiol 2011, 77:6694-6698.

36. Camu N, De Winter T, Addo SK, Takrama JS, Bernaert H, De Vuyst L: Fermentation of cocoa beans: influence of microbial activities and polyphenol concentrations on the flavour of chocolate. J Sci Food Agric 2008, 88:2288-2297.

37. Lefeber T, Janssens M, Camu N, De Vuyst L: Kinetic analysis of strains of lactic acid bacteria and acetic acid bacteria in cocoa pulp simulation media toward development of a starter culture for cocoa bean fermentation. Appl Environ Microbiol 2010, 76:7708-7716.

38. Lefeber T, Papalexandratou Z, Gobert W, Camu N, De Vuyst L: On-farm implementation of a starter culture for improved cocoa bean fermentation and its influence on the flavour of chocolates produced thereof. Food Microbiol 2012, 30:379-392.

39. Hendrickson H, Lawrence JG: Selection for chromosome architecture in bacteria. J Mol Evol 2006, 62:615-629.

40. Gao F, Zhang C-T: Ori-finder: a web-based system for finding oriCs in unannotated bacterial genomes. BMC Bioinforma 2008, 9:79.

41. Hendrickson H, Lawrence JG: Mutational bias suggests that replication termination occurs near the dif site, not at ter sites. Mol Microbiol 2007, 64:42-56.

42. Canchaya C, Proux C, Fournous G, Bruttin A, Brüssow H: Prophage genomics. Microbiol Mol Biol Rev 2003, 67:238-276

43. Takemura $H$, Horinouchi S, Beppu T: Novel insertion sequence IS1380 from Acetobacter pasteurianus is involved in loss of ethanol-oxidizing ability. J Bacteriol 1991, 173:7070-7076.

44. Ardhana MM, Fleet $\mathrm{GH}$ : The microbial ecology of cocoa bean fermentations in Indonesia. Int J Food Microbiol 2003, 86:87-99.

45. Schwan RF, Rose AH, Board RG: Microbial fermentation of cocoa beans, with emphasis on enzymatic degradation of the pulp. J Appl Bacteriol Symposium Supplement 1995, 79:96S-1075.

46. Kanchanarach $\mathrm{W}$, Theeragool G, Inoue T, Yakushi T, Adachi O, Matsushita K: Acetic acid fermentation of Acetobacter pasteurianus: relationship between acetic acid resistance and pellicle polysaccharide formation. Biosci Biotechnol Biochem 2010, 74:1591-1597. 
47. Kanchanarach W, Theeragool G, Yakushi T, Toyama H, Adachi O, Matsushita K: Characterization of thermotolerant Acetobacter pasteurianus strains and their quinoprotein alcohol dehydrogenases. Appl Microbiol Biotechnol 2010, 85:741-751.

48. Cleenwerck I, De Vos P: Polyphasic taxonomy of acetic acid bacteria: an overview of the currently applied methodology. Int J Food Microbio/ 2008, 125:2-14

49. Chandra Raj K, Ingram L, Maupin-Furlow J: Pyruvate decarboxylase: a key enzyme for the oxidative metabolism of lactic acid by Acetobacter pasteurianus. Arch Microbiol 2001, 176:443-451.

50. Argüelles JC: Physiological roles of trehalose in bacteria and yeasts: a comparative analysis. Arch Microbiol 2000, 174:217-224.

51. Booth IR, Edwards MD, Black S, Schumann U, Miller S: Mechanosensitive channels in bacteria: signs of closure? Nat Rev Microbiol 2007, 5:431-440.

52. Kondo K, Beppu T, Horinouchi S: Cloning, sequencing, and characterization of the gene encoding the smallest subunit of the three-component membrane-bound alcohol dehydrogenase from Acetobacter pasteurianus. J Bacteriol 1995, 177:5048-5055.

53. Gupta A, Singh VK, Qazi GN, Kumar A: Gluconobacter oxydans: its biotechnological applications. J Mol Microbiol Biotechnol 2001, 3:445-456.

54. Shinagawa E, Matsushita K, Adachi O, Ameyama M: Purification and characterization of D-sorbitol dehydrogenase from membrane of Gluconobacter suboxydans var. a. Agric Biol Chem 1982, 46:135-141.

55. Garcia-Armisen T, Vercammen K, Rimaux T, Vrancken G, De Vuyst L, Cornelis P: Identification of a five-oxidoreductase-gene cluster from Acetobacter pasteurianus conferring ethanol-dependent acidification in Escherichia coli. Microbiology Open 2012, 1:25-32.

56. Greenfield S, Claus GW: Nonfunctional tricarboxylic acid cycle and the mechanism of glutamate biosynthesis in Acetobacter suboxydans. J Bacteriol 1972, 112:1295-1301.

57. Sanders C, Turkarslan S, Lee D-W, Onder O, Kranz RG, Daldal F: The cytochrome $\mathrm{c}$ maturation components $\mathrm{CcmF}, \mathrm{CcmH}$, and $\mathrm{Ccml}$ form a membrane-integral multisubunit heme ligation complex. J Biol Chem 2008, 283:29715-29722.

58. Saeki A, Matsushita K, Takeno S, Taniguchi M, Toyama H, Theeragool G, Lotong N, Adachi O: Enzymes responsible for acetate oxidation by acetic acid bacteria. Biosci Biotechnol Biochem 1999, 63:2102-2109.

59. Mullins EA, Francois JA, Kappock TJ: A specialized citric acid cycle requiring succinyl-coenzyme $A(C o A)$ :acetate CoA-transferase (AarC) confers acetic acid resistance on the acidophile Acetobacter aceti. J Bacteriol 2008, 190:4933-4940.

60. Nakano S, Fukaya M, Horinouchi S: Putative $A B C$ transporter responsible for acetic acid resistance in Acetobacter aceti. Appl Environ Microbiol 2006 72:497-505.

61. Deeraksa A, Moonmangmee S, Toyama H, Yamada M, Adachi O, Matsushita K: Characterization and spontaneous mutation of a novel gene, polE, involved in pellicle formation in Acetobacter tropicalis SKU1100. Microbiology 2005, 151:4111-4120.

62. Ali IAl, Akakabe Y, Moonmangmee S, Deeraksa A, Matsutani M, Yakushi T, Yamada M, Matsushita K: Structural characterization of pellicle polysaccharides of Acetobacter tropicalis SKU1100 wild type and mutant strains. Carbohydr Polym 2011, 86:1000-1006.

63. Greenberg DE, Porcella SF, Zelazny AM, Virtaneva K, Sturdevant DE, Kupko JJ, Barbian KD, Babar A, Dorward DW, Holland SM: Genome sequence analysis of the emerging human pathogenic acetic acid bacterium Granulibacter bethesdensis. J Bacteriol 2007, 189:8727-8736.

64. Constantine CZ, Starks CM, Mill CP, Ransome AE, Karpowicz SJ, Francois JA, Goodman RA, Kappock TJ: Biochemical and structural studies of $N^{5}$ carboxyaminoimidazole ribonucleotide mutase from the acidophilic bacterium Acetobacter aceti. Biochemistry 2006, 45:8193-8208.

65. Francois JA, Kappock TJ: Alanine racemase from the acidophile Acetobacter aceti. Protein Expr Purif 2007, 51:39-48.

66. Matsutani M, Nishikura M, Saichana N, Hatano T, Masud-Tippayasak U, Theergool G, Yakushi T, Matsushita K: Adaptive mutation of Acetobacter pasteurianus SKU1108 enhances acetic acid fermentation ability at high temperature. J Biotechnol 2013, 165:109-119.

67. Ravyts F, Barbuti S, Frustoli MA, Parolari G, Saccani G, de Vuyst L, Leroy F: Competitiveness and antibacterial potential of bacteriocin-producing starter cultures in different types of fermented sausages. J Food Prot 2008, 71:1817-1827
68. Gordon D, Abajian C, Green P: Consed: a graphical tool for sequence finishing. Genome Res 1998, 8:195-202.

69. Husemann P, Stoye J: R2cat: synteny plots and comparative assembly. Bioinformatics 2010, 26:570-571.

70. Meyer F, Goesmann A, McHardy AC, Bartels D, Bekel T, Clausen J, Kalinowski J, Linke B, Rupp O, Giegerich R, Puhler A: GenDB - an open source genome annotation system for prokaryote genomes. Nucleic Acids Res 2003, 31:2187-2195.

71. Delcher AL, Harmon D, Kasif S, White O, Salzberg SL: Improved microbial gene identification with GLIMMER. Nucleic Acids Res 1999, 27:4636-4641.

72. Badger JH, Olsen GJ: CRITICA: coding region identification tool invoking comparative analysis. Mol Biol Evol 1999, 16:512-524

73. Suzek BE, Ermolaeva MD, Schreiber M, Salzberg SL: A probabilistic method for identifying start codons in bacterial genomes. Bioinformatics 2001, 17:1123-1130.

74. Lowe TM, Eddy SR: tRNAscan-SE: a program for improved detection of transfer RNA genes in genomic sequence. Nucleic Acids Res 1997, 25:955-964.

75. Linke B, McHardy AC, Neuweger H, Krause L, Meyer F: REGANOR: A gene prediction server for prokaryotic genomes and a database of high quality gene predictions for prokaryotes. App/ Bioinformatics 2006, 5:193-198.

76. Boeckmann B, Bairoch A, Apweiler R, Blatter MC, Estreicher A, Gasteiger E, Martin MJ, Michoud K, O'Donovan C, Phan I, Pilbout S, Schneider M: The SWISS-PROT protein knowledgebase and its supplement TrEMBL in 2003. Nucleic Acids Res 2003, 31:365-370.

77. Bateman A, Coin L, Durbin R, Finn RD, Hollich V, Griffiths-Jones S, Khanna A, Marshall M, Moxon S, Sonnhammer ELL, Studholme DJ, Yeats C, Eddy SR: The Pfam protein families database. Nucleic Acids Res 2004, 32:D138-D141.

78. Kanehisa M, Goto S: KEGG: Kyoto encyclopedia of genes and genomes. Nucleic Acids Res 2000, 28:27-30.

79. Haft DH, Selengut JD, White O: The TIGRFAMs database of protein families. Nucleic Acids Res 2003, 31:371-373.

80. Bendtsen JD, Nielsen H, von Heijne G, Brunak S: Improved prediction of signal peptides: signalP 3.0. J Mol Biol 2004, 340:783-795.

81. Dodd IB, Egan JB: Improved detection of helix-turn-helix DNA-binding motif in protein sequences. Nucleic Acids Res 1990, 18:5019-5026.

82. Krogh A, Larsson B, von Heijne G, Sonnhammer ELL: Predicting transmembrane protein topology with a hidden Markov model: application to complete genomes. J Mol Biol 2001, 305:567-580.

83. Tatusov RL, Natale DA, Garkavtsev IV, Tatusova TA, Shankavaram UT, Rao BS, Kiryutin B, Galperin MY, Fedorova ND, Koonin EV: The COG database: new developments in phylogenetic classification of proteins from complete genomes. Nucleic Acids Res 2001, 29:22-28.

84. Harris MA, Clark J, Ireland A, Lomax J, Ashburner M, Foulger R, Eilbeck K, Lewis S, Marshall B, Mungall C, Richter J, Rubin GM, Blake JA, Bult C, Dolan M, Drabkin H, Eppig JT, Hill DP, Ni L, Ringwald M, Balakrishnan R, Cherry JM, Christie KR, Costanzo MC, Dwight SS, Engel S, Fisk DG, Hirschman JE, Hong EL, Nash RS, et al: The Gene Ontology (GO) database and informatics resource. Nucleic Acids Res 2004, 32:D258-D261.

85. Carver T, Thomson N, Bleasby A, Berriman M, Parkhill J: DNAPlotter: circular and linear interactive genome visualization. Bioinformatics 2009, 25:119-120.

86. Grissa I, Vergnaud G, Pourcel C: CRISPRFinder: a web tool to identify clustered regularly interspaced short palindromic repeats. Nucleic Acids Res 2007, 35:W52-W57.

87. Castro C, Cleenwerck I, Trček J, Zuluaga R, De Vos P, Caro G, Aguirre R, Putaux J-L, Gañán P: Gluconacetobacter medellinensis sp. nov., celluloseand non-cellulose producing acetic acid bacteria isolated from vinegar. Int J Syst Evol Microbiol 2012, 63:1119-1125.

88. Blom J, Albaum S, Doppmeier D, Pühler A, Vorhölter F-J, Zakrzewski M, Goesmann A: EDGAR: a software framework for the comparative analysis of prokaryotic genomes. BMC Bioinforma 2009, 10:1-14.

89. Carver TJ, Rutherford KM, Berriman M, Rajandream MA, Barrell BG, Parkhill J: ACT: the Artemis Comparison Tool. Bioinformatics 2005, 21:3422-3423.

90. Altschul SF, Gish W, Miller W, Myers EW, Lipman DJ: Basic local alignment search tool. J Mol Biol 1990, 215:403-410

\section{doi:10.1186/1471-2164-14-526}

Cite this article as: Illeghems et al:: Complete genome sequence and comparative analysis of Acetobacter pasteurianus 386B, a strain welladapted to the cocoa bean fermentation ecosystem. BMC Genomics $201314: 526$ 